\title{
Prediction of Potential Fishing Zones for Skipjack Tuna During the Northwest Monsoon Using Remotely Sensed Satellite Data
}

\author{
Mukti Zainuddin, Safruddin¹, Muhammad Banda Selamat ${ }^{1}$, Aisjah Farhum¹ and Sarip Hidayat² \\ ${ }^{1}$ Faculty of Marine Science and Fisheries, Hasanuddin University \\ Jl. Perintis Kemerdekaan km 10 Tamalanrea, Makassar 90245, Indonesia \\ IIndonesian National Institute of Aeronautics and Space (LAPAN) Parepare \\ Jl. Jend. A. Yani KM. 6, Kota Parepare, 91112 Indonesia \\ Email: mukti_fishocean@yahoo.co.id
}

\begin{abstract}
One of economically important fish in the Bay of Bone is Skipjack tuna which their distribution and migration are influenced by surrounding environment. This study aims to investigate the relationship between skipjack tuna and their environments, and to predict potential fishing zones (PFZs) for the fish in the Bone Bay-Flores Sea using satellite-based oceanography and catch data. Generalized additive models (GAMs) were used to assess the relationship. A generalized linear model(GLM) constructed from GAMs was used for prediction. Monthly mean sea surface temperature (SST) and chlorophyll-a during the northwest monsoon (December-January) together with catch data were used for the year 2012-2013. We used the GAMs to assess the effect of the environment variables on skipjack tuna CPUE (catch per unit effort). The best GLM was selected to predict skipjack tuna abundance. Results indicated that the highest CPUES (fish/trip) occurred in areas where SST and chlorophyll-a ranged from $29.5^{\circ}-31.5^{\circ} \mathrm{C}$ and $0.15-0.25 \mathrm{mg} \mathrm{m}^{-3}$, respectively. The PFZs for skipjack were closely related to the spatial distribution of the optimum oceanographic conditions and these mainly developed in three locations, northern area of Bone Bay in December, in the middle area of the bay $\left(4^{\circ}-5.5^{\circ} \mathrm{S}\right.$ and $\left.120.5^{\circ}-121.5^{\circ} \mathrm{E}\right)$ during January and moved to the Flores Sea in February. The movement of skipjack concentration was consistent with the fishery data. This suggests that the dynamics of the optimum oceanographic signatures provided a good indicator for predicting feeding grounds as hotspot areas for skipjack tuna in Bone Bay-Flores Sea during northwest monsoon.
\end{abstract}

Keywords: skipjack tuna, potential fishing zones, satellite based-oceanographic data, Northwest monsoon

\section{Introduction}

The Bone Bay- Flores Sea located in the central Indonesian Seas is one of the most biologically productive areas in the tropical region (Figure 1.). This area is also one of the main pathways the Indonesian Through Flow (ITF) and is strongly influenced by the Asian monsoon i.e. southeast monsoon and northwest monsoon (Gordon, 2005). The study area is also well known as one of the most productive skipjack tuna fishing grounds in Indonesian waters (Mallawa, 2009).

Skipjack tuna is the most important species targeting by fishermen in the Bay of Bone, South Sulawesi. The distribution and migration of this species are strongly influenced by oceanographic factors such as distributions of SST and chlorophyll-a (hereafter Chl-a) concentration (Zainuddin, 2011a,b). Sea surface temperature (SST) can influence the geographical range of marine species, the observed association of albacore with ocean thermal structures cannot be explained by temperature per se, but involve also other behavioral mechanisms linked with feeding activity (Zainuddin et al., 2008). In respect to tuna ecology, SST is an important variable for thermoregulation process and physiological adaptation for tuna, while Chl-a concentration is an important indicator for tuna forage habitat (Polovina et al., 2017). The physical oceanographic parameter is one of important oceanographic parameters to study skipjack tuna habitat in tropical region. Skipjack migration route and habitat in the Bone Bay corresponds to the movement of optimum range SST (Zainuddin et al., 2013).

A combined satellite remote sensing (SRS) and geographic information system (GIS) provides a powerful tool to characterize potentially marine fish habitats particularly for highly migratory tuna (Mugo et al., 2010). SST and Chl-a derived from satellite data are determinant factors in predicting tuna forage and their habitat in Western North Pacific Ocean (Polovina et al., 2001; Zainuddin et al., 2008). Temperature preferences for skipjack in 


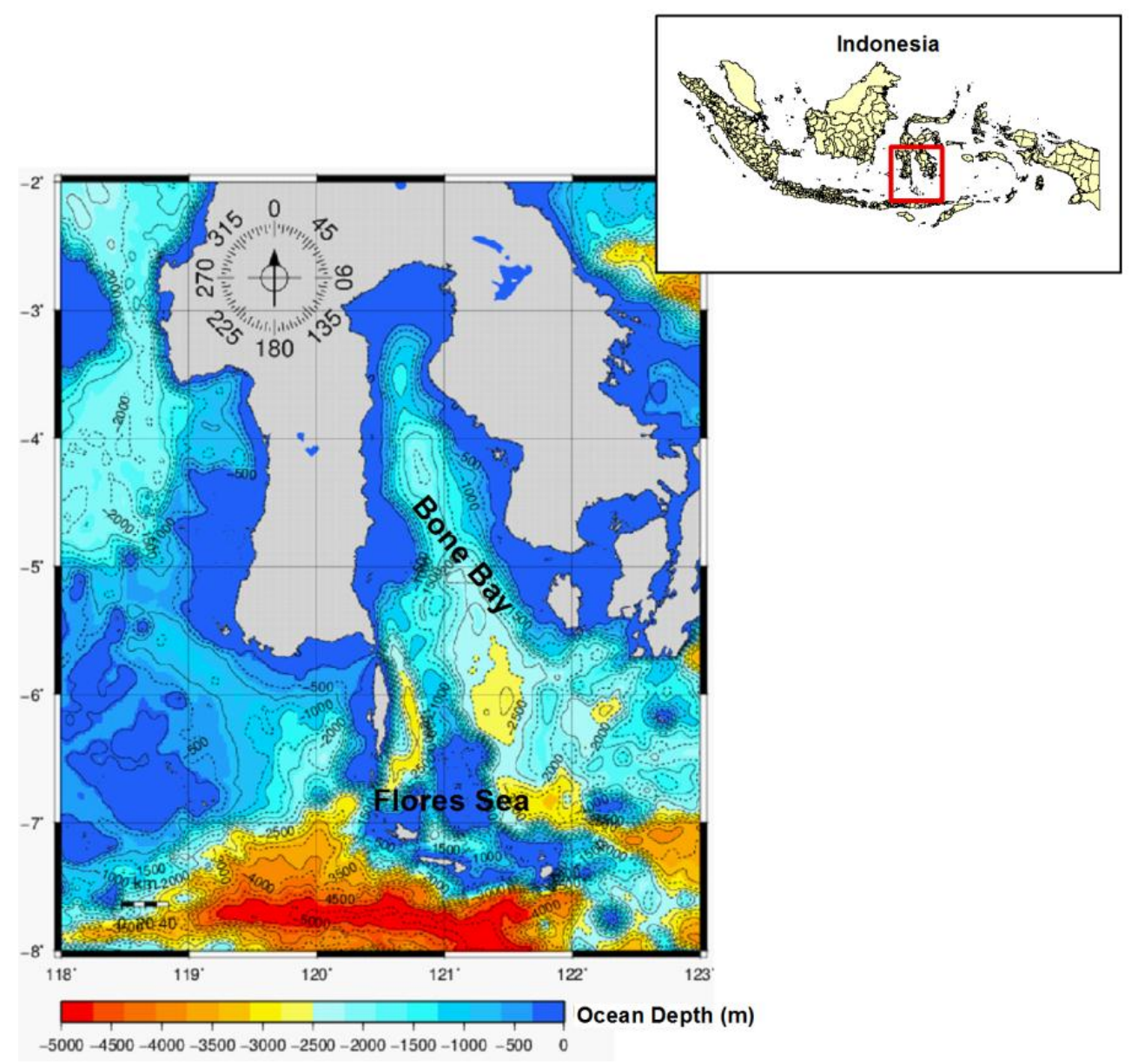

Figure 1. Location map of the area investigated in Bone Bay-Flores Sea within Indonesian Waters

western North Pacific and the southwest Atlantic (Brazilian waters) range from 20.5 to $26^{\circ} \mathrm{C}$ and from 22 to $26.5^{\circ} \mathrm{C}$ (Andrade and Garcia, 1999; Mugo et al., 2010). Off coast of Japan, the Chl-a associates with skipjack in areas of oligotrophic waters (surface Chl-a 0.08-0.18, 0.22-0.27 and 0.3-0.37 mg.m ${ }^{-3}$ ) (Mugo et al., 2010). Our previous study indicates that skipjack tuna during the south-east monsoon associates well with preferred SST and chlorophyll-a concentration (Zainuddin et al., 2013). An investigation of the potential fishing zone for skipjack tuna during the north-west monsoon is still unclear. Therefore, the objectives of this study are to explore the relationship between oceanographic factors and skipjack tuna abundance, to predict the potential fishing zones the north-west monsoon.

\section{Materials and Methods}

\section{Pole and line fishery data}

The pole and line fishery, extending from the Bone bay to Flores Sea, catches skipjack tuna during year round. Our database indicates that geographical distributions of skipjack in the Bone Bay to Flores Sea by latitude mainly locate about 3$8^{\circ} \mathrm{S}$ and the high skipjack abundance occurs in southeast monsoon (Zainuddin et al., 2013). In this study we compiled from daily into monthly fishery data during northwest monsoon (DecemberFebruary).The catch data, including skipjack catch numbers per unit effort (CPUE) and fishing position were geo-referenced with high resolution of both longitude and latitude. One trip in the fishing operation usually consisted of 2-4 fishing sets (hauling). Therefore, the unit of fishing efforts in this study used the fishing set to improve the accuracy (minimizing deviation standard in effort). We obtained these data by following fishing operations during the period.

\section{Satellite remote sensing data}

The physical and biological environmental data used to describe the oceanographic condition around the fishing locations are surface chlorophylla concentration and sea surface temperature (SST). These data have the same spatial and temporal resolution. 
Aqua/MODIS (Moderate Resolution Imaging Spectroradiometer) level 3 standard mapped images were used to estimate sea surface Chl-a concentration. These data were obtained from NASA GSFC's Distributed Active Archive Center (DAAC) (http://oceancolor.gsfc.nasa.gov/). We used Global Area Coverage (GAC), monthly composite MODIS images with a spatial resolution of about $4 \times 4 \mathrm{~km}$ for the period from December 2012 to February 2013.

In this study, Aqua/MODIS sea surface temperature (SST) was used to estimate temperature along the study area. The NASA distributes Standard Mapped Image (SMI) SST level 3 binary data with HDF (Hierarchical Data Format) format. This study used the satellite data with monthly temporal resolution during December 2012 to February 2013 , at $0.044^{\circ}$ of longitude and latitude spatial resolution. Data were processed using IDL (Interactive Data Language) software package to get image data throughout the area.

\section{Prediction of potential fishing zones}

To predict spatial patterns of potential fishing zone for skipjack tuna, statistical models were applied. These models were built by combining generalized additive model (GAM) and linear model/generalized linear model (GLM). This study constructed the linear model based on the nature of the relationship between skipjack CPUE as the response variable and SST and Chl-a as predictor variables resulting from a GAM with the least different of residual deviance (Zainuddin et al., 2008). Despite the GAM may explain variance of CPUE more effective and flexible than the linear model (GLM), the model has no analytical form (Mathsoft, 2000). A linear model provides a way of estimating a function of mean response (CPUE) as a linear function of some set of covariates. Therefore, this study used the GLM fit to predict a spatial pattern of skipjack CPUE. The first step to get the spatial predictive model was to construct GAM as an exploratory tool. This step was used to identify the shapes of the relationships between environmental factors and skipjack CPUE as it was most likely that the expected relationships are non-linear. The second, once the shape of the relationships between the skipjack CPUE and each predictor (SST and Chla) were identified, the appropriate functions were used to parameterize these shapes in the linear model (Zainuddin et al., 2008;2013). The shapes resulting from the GAM were reproduced as closely as possible using the piecewise linear model. Statistical Models of the GAM and the linear model respectively: $\log ($ срие +1$)=\alpha+s(S S T)+s(C h l-a)+\varepsilon$

$\log ($ срие +1$)=\beta_{0}+\beta_{1}(S S T)+\beta_{2}(C h l-a)+\varepsilon$

where $\alpha$ and $\beta$ Oare constant, $s($.$) is a spline smooth$ function of the predictor variables (SST and Chl-a) and $\varepsilon$ is a random error term, $\beta 1$ and $\beta 2$ is the vector of model coefficients. The constant intercept terms were computed using gam and glm functions in $\mathrm{R}$ Language. All statistical analyses were carried out using $\mathrm{R}$ Language version 3.1.2.

\section{Results and Discussion}

SST was highest in December and the relatively lower SSTs were more apparent in January when the skipjack tuna were widely distributed along the Bone Bay (Figure2.). During northwest monsoon (December-February), the fishing sets occupied areas where SST ranged from $28.5^{\circ} \mathrm{C}$ to $32.5^{\circ} \mathrm{C}$ and the skipjack CPUEs were found to be highest at about $30{ }^{\circ} \mathrm{C}$ (Figure 3). The highest CPUEs were obtained in December.

Figure 2 also shows that during the northwest monsoon, the fishing operations aggregated in areas of chl-a concentrations of $0.075-0.25 \mathrm{mg}^{-\mathrm{m}^{-3}}$. The highest CPUEs occurred in the fishing grounds of less than 0.25 mg. $\mathrm{m}^{-3}$. The histogram graph confirmed that the highest fishing frequency and skipjack CPUE were found at $0.2 \mathrm{mg} \cdot \mathrm{m}^{-3}$ (Figure 3.). Fishing data CPUE are often used as an index of fish occurrence and abundance (Zainuddin et al., 2006) and therefore high CPUEs can be said to indicate preferred areas for a species (Zainuddin et al., 2008). Whilst, fishing ground chlorophyll environment relationship during northwest monsoon showed that most fishing sets have a good association with surface chlorophyll-a of 0.125 0.275 mg. $\mathrm{m}^{-3}$ (Figure 3). The latitudinal displacement of the fishing sets during the northwest monsoon corresponded with the spatial dynamics of relatively lower Chl-a concentration and relatively warmer SST. Figures 2 and 3 showed the highest CPUEs during the west monsoon were consistent with the movement of both optimum surface chlorophyll-a and SST. These evidences reflect that the Chl-a and SST signatures are capable of detecting potential habitats (hotspot) for tuna species such as upwelling area, frontal zone and eddy field (Zainuddin et al., 2006; Mugo et al., 2010).

GAM plots could be interpreted as the individual effect of each predictor variable on CPUE as a scatter plot (Figure 4:upper). Rug plots on the horizontal axis represent observed data points and 



Figure 2. The spatial distribution of skipjack CPUE (fish/fishing sets) from the pole and line fishery shown as dots for December 2012- February 2013 overlain on the MODIS SST and chlorophyll concentration images 

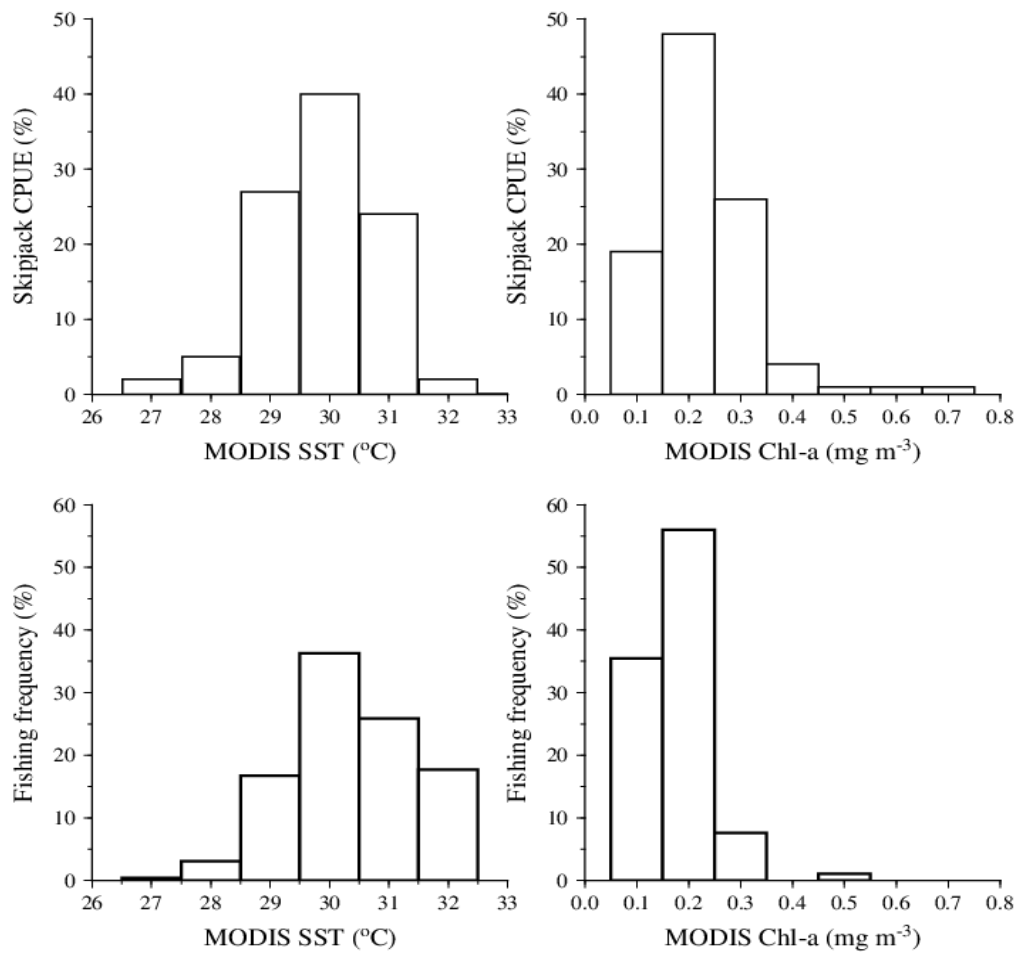

Figure 3. Histogram of skipjack CPUE (upper) and fishing frequency of skipjack fishery (lower) in relation to both SST and Chl-a.
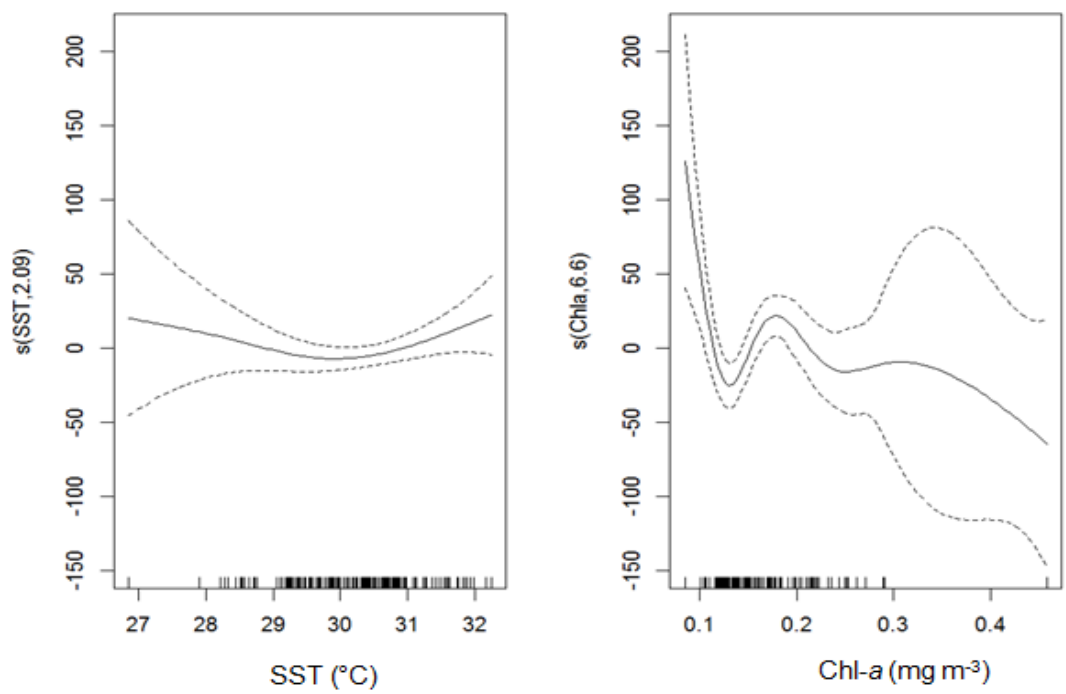

Figure 4. Generalized additive model derived effect of SST and Chl-a on nominal skipjack CPUE deviance (upper). Both independent variables are included in the GAM. Dashed lines indicate 95\% confidence bands.

the fitted function is shown by the thick line (Figure 4). The dashed line indicates the 95\% confidence bands. Both SST and Chl-a had a negative effect on skipjack CPUE. It is important to see that skipjack CPUE increases significantly with Chl-a from 0.10 to $0.20 \mathrm{mg} \cdot \mathrm{m}^{-3}$ and SST from 30 to $31^{\circ} \mathrm{C}$. Our result indicated that $\mathrm{Chl}-\mathrm{a}$ is the stronger predictor than
SST. The SST and Chl-a values outside the preferred oceanographic ranges is unclear because the reduced density of fishery data points leads to larger standard error ranges (wider confidence bands).

The GAM plots (rug plots) are substantially reinforced by the histogram graphs (Figure 3.). From 
this graph, distribution of Chl-a data presented more specific and sharper than that of SST. It implies that skipjack tuna are more tolerable in physiological adaptation and temperature limit in the equatorial region. It is more probable that skipjack tuna captured within study area have various sizes. The preferred SST range within the Bone Bay-Flores Seais higher than in subtropical waters (Mugo et al., 2010), but it has specific in surface Chl-a range.

Figure 5 shows the spatial prediction of skipjack CPUE and the potential fishing zones during the northwest monsoon. The predicted CPUE for skipjack tuna present a southward displacement from December (in the middle of Bone Bay), extending to southern area in January, after which there is a highly potential fishing zones formed in Bone Bay $\left(121^{\circ} \mathrm{E}-121.5^{\circ} \mathrm{E}\right.$ and $\left.4^{\circ} \mathrm{S}-4.5^{\circ} \mathrm{S}\right)$. The potential fishing zones developed when nutrient rich waters probably stimulating by the seasonal upwelling well enhanced. In February, relatively high skipjack CPUEs are again concentrated back to northern area of Bone Bay. A good feeding ground was well formed during this period and leads to
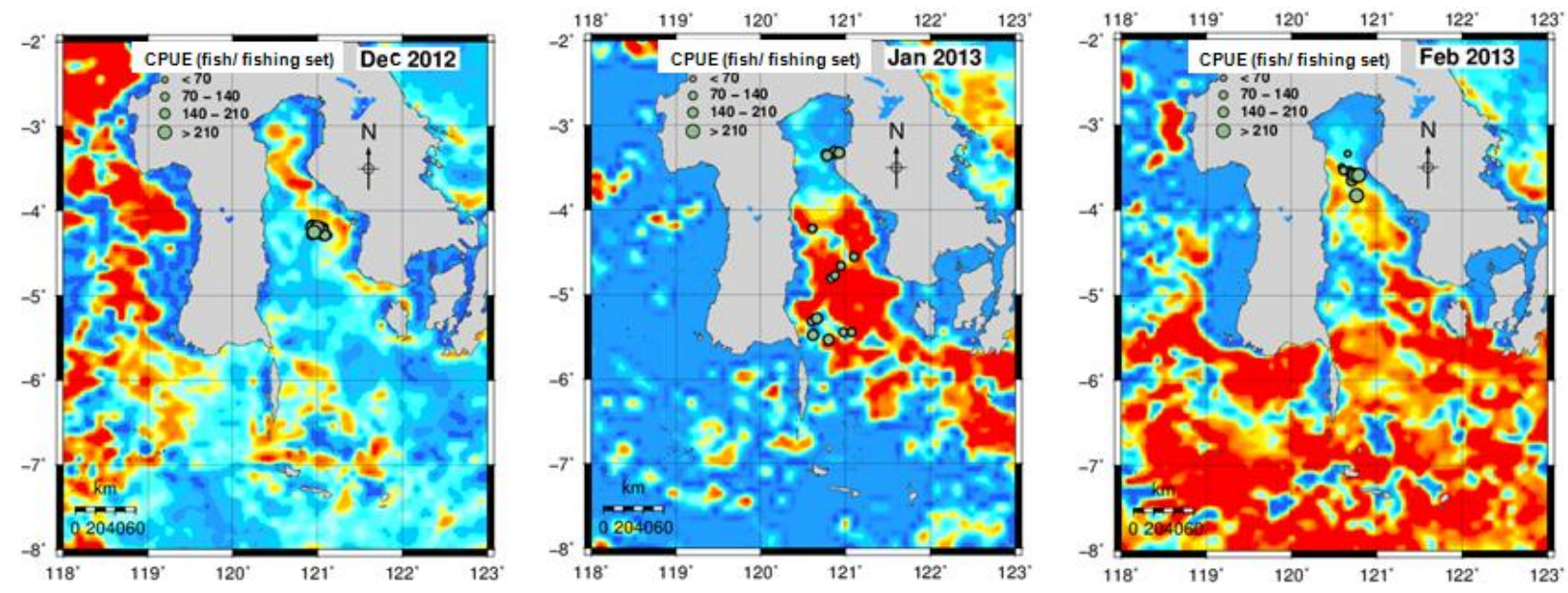

Figure 5. The spatial distribution of skipjack CPUE (fish/fishing sets) from the pole and line fishery shown as dots for December 2012-February, 2013 overlain on the predicted CPUE derived GAM -GLM (linear model). Note.
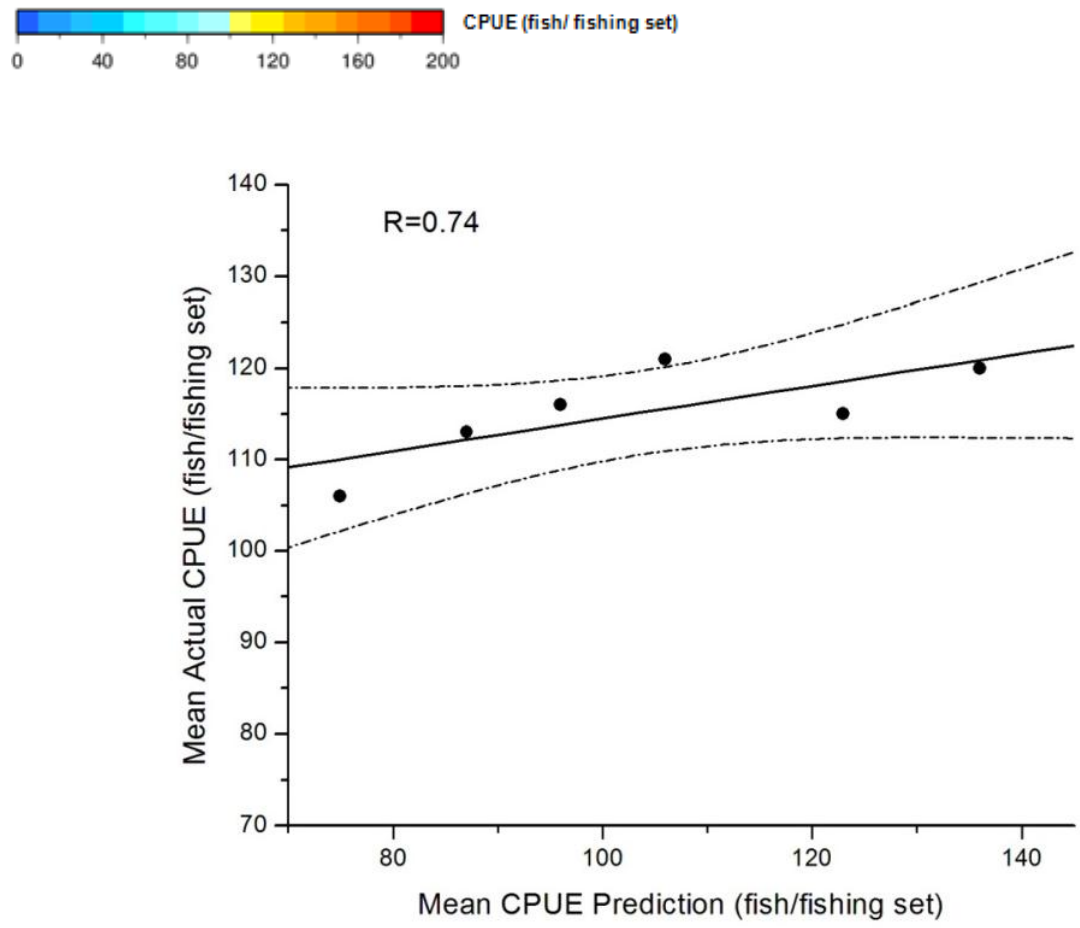

Figure 6. A scatter plot of pooled monthly observed against predicted CPUE values $(P<0.05, r=0.74)$. Dash lines signify $95 \% C L$. 
significantly increase CPUE particularly in December. During this month, the potential fishing zones developed and these were accessible for fishery activities where the CPUE were highest (Figure 5.). This is clearly characterized by the development of preferred oceanographic ranges (SST and Chl-a). The predicted values lie from zero to approximately 200 fish per fishing set. The predicted CPUE map indicates that skipjack CPUE was highest in December and was consistent with the fishing data overlaid on the map throughout the northwest monsoon.

The relationship between actual CPUE and predicted CPUE pooled monthly was statically significant $(P<0.05)$ (Figure6). Predicted CPUEs show an appreciable concurrence with actual pole and line fishing locations during the northwest monsoon (2012-2013). This fact showed consistent increases in mean CPUE over the study period, suggesting that the model performed fairly well in predicting skipjack potential areas.

\section{Conclusions}

Using satellite-based oceanographic and catch data, the PFZs for skipjack were closely related to the spatial distribution of the optimum value of SST and Chl-a ranges. The potential fishing areas were predicted in three locations, northern area of Bone Bay (December), in the middle area of the bay (January) and Flores Sea in February. This suggests that the key oceanographic signatures of both SST and Chl-a provide a good indicator for predicting potential fishing grounds for skipjack tuna in Bone Bay-Flores Sea during northwest monsoon.

\section{Acknowledgements}

We are greatly indebted to Rini Sahni Putri dan Nur Indah Reskyanti for all assistances in collecting the pole and line fishery data in Bone Bay and Flores Sea. We also appreciate the use of AQUAMODIS SST and chlorophyll-a data sets, downloaded from the ocean color portal (http://oceancolor.gsfc.nasa.gov). This work was partly supported to MZ. by the National Competitive Research Grant (Competence Grant-Hibah Kompetensi 2015/2016), Directorate General of Higher Education.

\section{References}

Andrade, H.A. \& Garcia, C.A.E. 1999. Skipjack tuna fishery in relation to sea surface temperature off the southern Brazilian coast. Fisheries Oceanogr. 8(4):245-254. doi: 10.1046/j.13 65-2419.1999.00107.x.

Mallawa, A., 2009. Pemetaan Daerah Penangkapan, Hubungan Habitat Selection dan best Fishing Ground. Bahan Ajar Program S3 IImu Pertanian minat Perikanan. Program Pasca Sarjana UNHAS. Tidak Dipulikasikan, pp.67.

Mathsoft. 1999. S-Plus 2000 guide to statistics: Data Analysis Products Devision, Mathsoft, Inc. Seattle, USA, pp.650.

Mugo, R., Saitoh, S.I., Nihira, A. \& Kuroyama, T 2010. Habitat characteristics of skipjack tuna (Katsuwonus pelamis) in the western North Pacific: a remote sensing perspective. Fisheries Oceanogr. 19(5):382-396. doi: 10.1111/ j.1365-2419.2010.00552.x.

Polovina, J.J., Howell, E., Kobayashi, D.R. \& Seki, M.P. 2001. The transition zone chlorophyll front, a dynamic global feature defining migration and forage habitat for marine resources. Prog. Oceanogr. 49(1-4):469-483. doi: 10.1016/S0079-6611(01)00036-2.

Polovina, J.J., Howell, E.A., Kobayashi, D.R. \& Seki, M.P. 2017. The Transition Zone Chlorophyll Front updated: Advances from a decade of research. Prog. Oceanogr. 150:79-85. doi: 10.1016/j.pocean.2015.01.006.

Gordon, A., 2005. Oceanography of the Indonesian Seas and Their Through flow.Oceanogr. 18(4):14-27. doi: 10.5670/oceanog.2005.01.

Zainuddin, M., Kiyofuji, H., Saitoh, K. \& Saitoh, S.I. 2006. Using multi-sensor satellite remote sensing and catch data to detect ocean hot spots for albacore (Thunnus alalunga) in the northwestern North Pacific. Deep-Sea Research Part II: Topical Studies in Oceanography, 53(34):419-431. doi:10.1016/j.dsr2.2006.01.007

Zainuddin, M., Saitoh, K. \& Saitoh, S.I. 2008. Ibacore (Thunnus alalunga) fishing ground in relation to oceanographic conditions in the western North Pacific Ocean using remotely sensed satellite data. Fisheries Oceanogr. 17(2): 61-73. doi: 10.1111/j.1365-2419.2008.00461.x

Zainuddin, M., 2011a. Skipjack tuna in relation to sea surface temperature and Chlorophyll-A concentratation of Bone Bay using remotely sensed satellite data. Jurnal IImu dan Teknologi Kelautan Tropis. 3(1): 82-90. 
Zainuddin, M. 2011b. Preliminary Findings on Distribution and Abundance of Flying fish in Relation to Oceanographic Conditions of Flores Sea Observed from Multi-spectrum Satellite Images. Asian Fisheries Sci. 24:20-30.

Zainuddin, M., Nelwan, A., Farhum, S.A., Hajar, M.A.I. \& Kurnia, M. 2013. Characterizing Potential
Fishing Zone of Skipjack Tuna during the Southeast Monsoon in the Bone Bay-Flores Sea Using Remotely Sensed Oceanographic Data. Int. J. Geosci. 4:259-266. doi: 10.4236/ijg.20 13.41A023. 